\title{
A simple method for positive pressure ventilation during fibreoptic intubation
}

\author{
J. Matthew Kynes, MD · Jonathan R. Meserve, MD • \\ David Selig, MD
}

Received: 12 November 2014/ Accepted: 16 February 2015/Published online: 17 March 2015

(c) Canadian Anesthesiologists' Society 2015

\section{To the Editor,}

When patients present in respiratory distress, respiratory support in the form of positive airway pressure is often required to maintain oxygenation and ventilation; however, it is frequently abandoned if awake fibreoptic intubation (FOI) is required. We present a case where commonly available airway adjuncts were used to secure a difficult airway while maintaining positive pressure support in an awake patient.

Two days after excision of an esophageal cyst, a 51-yrold male presented with a thoracic duct leak causing an enlarging collection of retropharyngeal lymphatic fluid. Given his symptoms of dyspnea, stridor, an inability to lay supine, and the presence of a large firm mass in close proximity to the trachea, a difficult airway was anticipated. Synchronous ventilation with an $\mathrm{Ambu}^{\circledR}$ bag (Adult Manual Resuscitator 2k8004, CareFusion Yorba Linda, CA, USA) was performed with the patient awake and sitting. Ventilation was briefly interrupted for airway topicalization with $4 \%$ lidocaine and placement of a Berman intubating airway (Vital Signs Inc., Totowa, NJ, USA). One clinician ventilated the patient's lungs continuously by Ambu bag, while another advanced a fibreoptic bronchoscope $(4.0 \mathrm{~mm})$ via an Aintree intubation catheter (C-CAE-19.0-56-AIC; $56 \mathrm{~cm}$, internal diameter $4.7 \mathrm{~mm}$; Cook Medical, Bloomington, IN, USA) together through a bronchoscope adapter (Rusch Double Swivel Connector $15 \mathrm{~mm}$; Teleflex Medical, Kingston, MA, USA) and then through a straight connector (Teleflex

J. M. Kynes, MD · J. R. Meserve, MD · D. Selig, MD ( $\varangle)$ Department of Anesthesiology, Perioperative and Pain Medicine, Brigham and Women's Hospital and Harvard Medical School, Boston, MA, USA

e-mail: dselig@partners.org
Multi Adaptor $15 \mathrm{~mm} \mathrm{M,} 22 \mathrm{~mm} \mathrm{M} / 15 \mathrm{~mm} \mathrm{~F}$ ) into the mask, Berman airway, and on through to the hypopharynx (Figure). Alignment of the mask and the Berman airway to allow passage of the bronchoscope was not difficult. The cords were directly topicalized with lidocaine via the bronchoscope before advancing into the trachea. No sedation was administered.

Everything but the Aintree catheter was then removed, and a size 8.0 reinforced endotracheal tube (ETT) was routed over the catheter using a modified Seldinger technique. The ETT position was confirmed with breath sounds and end-tidal $\mathrm{CO}_{2}$ measurement. Oxygen saturation by pulse oximetry remained $>92 \%$ throughout. A post-intubation computed tomography revealed a $16 \times 8.8 \times 4.9 \mathrm{~cm}$ retropharyngeal (likely lymphatic) fluid collection extending from the level of the tongue into the mediastinum. The patient underwent mediastinal exploration with ligation of the thoracic duct and made a full recovery.

In this case, findings on imaging and clinical exam predicted difficult intubation with a risk for significant hypoxia and hypercarbia during an anticipated prolonged intubation attempt. Our innovative technique using commonly available equipment to provide ventilatory support during awake FOI produced safer intubating conditions. The technique can be used with any method of mask ventilation provided a bronchoscope adapter can be inserted with a relatively straight path to the oral cavity.

Alternative techniques utilizing commonly available equipment for awake intubations have also been described. One technique involves inflating the cuff of an ETT within the connector orifice of a facemask and connecting a bronchoscope adapter to the ETT connector. ${ }^{1}$ Assisted ventilation during bronchoscopy is performed, and intubation is accomplished by advancing the ETT over the bronchoscope through the mask and into the larynx. 


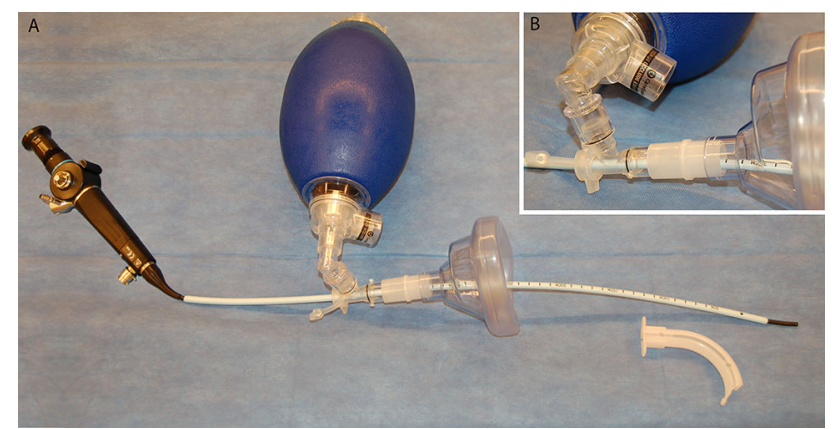

Figure A fully assembled intubating apparatus: A) Close-up view of the bronchoscope port and B) assembled bronchoscope, Aintree intubating catheter, bronchoscopy adapter, straight connector, bag valve mask, and Berman airway

This technique carries a theoretical risk of ETT cuff failure as it is inflated against hard surfaces.

More recently, a method was described in which a guidewire was deployed via the working channel of a bronchoscope, and the Seldinger technique was used to route the ETT over the guidewire. ${ }^{2}$ Nevertheless, this technique requires an intubating wire, and limitations have been published regarding wire-guided intubations with the Seldinger technique. Such limitations include an inability to pass the ETT over a wire into the trachea due to a mismatch of wire and tube size and kinking of the wire.

Regardless of the technique used, the benefits of positive pressure assistance during bronchoscopy, an integral part of FOI, are well documented. For example, in patients with advanced pulmonary disease, the use of positive pressure assistance before and during bronchoscopy improves oxygenation compared with positive pressure assistance only before such procedures. ${ }^{3}$

Our technique is another option for safely securing the airway in patients with compromised upper airway anatomy. We anticipate that this technique would also be useful in patients with underlying lung disease who need respiratory support and require tracheal intubation. In our view, this technique warrants further study because of its advantages in performance and the availability of the components.

Conflict of interest None declared.

Funding None.

\section{References}

1. Higgins MS, Marco AP. An aid in oral fiberoptic intubation. Anesthesiology 1992; 77: 1236-7.

2. Heier JM, Schroeder KM, Galgon RE, Arndt GA. Wire-guided (Seldinger technique) intubation through a face mask in urgent, difficult and grossly distorted airways. Saudi J Anaesth 2012;6: 292-4.

3. Antonelli $M$, Conti $G$, Rocco $M$, et al. Noninvasive positivepressure ventilation vs. conventional oxygen supplementation in hypoxemic patients undergoing diagnostic bronchoscopy. Chest 2002; 121: 1149-54. 